concentration and precipitation of dextran in the proximal tubule and the formation of casts, which obstruct the flow of tubular fluid. ${ }^{3}$ Dextran solutions may perhaps cause a functional reduction in glomerular filtration by raising plasma oncotic pressure ${ }^{4}$ and, after filtration and concentration in the proximal tubule, by raising tubular hydrostatic pressure. ${ }^{5}$ Plasma oncotic pressure was normal in our patient, although we did not measure it until 48 hours after the operation and thus may have missed a transient increase. This, however, would have been only a contributory factor in the development of the renal failure as there was clear evidence of severe structural damage to the kidney.

We recommend that infusions of large amounts of
Gelofusine should be avoided in patients with persistently low renal perfusion pressures or rates of urine flow.

1 Michie AJ, Koop CE, Walker JM, Ragni MC, Tracy J. Renal haemodynamics following intravenous administration of gelatin. If Appl Physiol 1952;4:67781.

2 Figueroa JE, Burgos-Calderon R. Renal toxicity of low molecular weight dextran: a review of the literature. $\mathcal{F}$ La State Med Soc 1974;126:425-8.

3 Chinitz JL, Kim KE, Onesti G, Swartz. C. Pathophysiology and prevention of dextran-40-induced anuria. F Lab Clin Med 1971;77:76-87.

4 Moran M, Kapsner C. Acute renal failure associated with elevated plasma oncotic pressure. $N$ Engl f Med 1987;317:150-3.

Mailloux L, Swartz CD, Capizzi R, et al. Acute renal failure after administration of low molecular weight dextran. $N$ Engl f Med 1967;277:1113-8.

(Accepted 26 fuly 1989)

\title{
Ranking of symptoms by patients with the irritable bowel syndrome
}

\section{G Maxton, J A Morris, P J Whorwell}

Department of Medicine, University Hospital of South Manchester, Manchester M20 8LR

D G Maxton, MRCP, lecturer J A Morris, MSC, senior medical statistician

P J Whorwell, FRCP, consultant physician Dr Whorwell.

BrMed f 1989;299:1138
Correspondence to:

Abdominal pain, distension, and an abnormal bowel habit are regarded as the main symptoms of irritable bowel syndrome. We found, however, that patients also complain of various other symptoms such as lethargy, backache, nausea, and urinary problems. We assessed the relative importance of all symptoms related to the syndrome by asking patients to rank them in order of severity.

\section{Patients, methods, and results}

We studied 100 consecutive outpatients with the irritable bowel syndrome ( 89 women, 11 men; aged 1874). An interview was conducted with the aid of 13 plastic cards each denoting a symptom (see table). One card specified a control symptom (dry skin) not known to be associated with the syndrome, and one card gave the patient an opportunity to specify an additional symptom. Patients were asked to select cards representing their symptoms and to rank the six most troublesome symptoms in order of severity. The most severe symptom scored six with subsequent symptoms being scored down to one. All symptoms suffered but not ranked were scored as zero. All patients were assessed with the hospital anxiety depression questionnaire. ${ }^{2}$ Relations between symptoms and the psychological assessment were examined with $\chi^{2}$ tests. A severity score (the sum of all the scores for a particular symptom divided by the number of

Ranking of symptoms by 100 patients with irritable bowel syndrome

\begin{tabular}{|c|c|c|c|c|c|c|}
\hline \multirow[b]{2}{*}{ Symptom } & \multirow{2}{*}{$\begin{array}{c}\text { No } \\
\text { with } \\
\text { symptom }\end{array}$} & \multicolumn{4}{|c|}{ No $\left(\%^{\star}\right)$ of patients with each symptom ranking it as: } & \multirow[b]{2}{*}{$\begin{array}{l}\text { Severity } \\
\text { score }\end{array}$} \\
\hline & & $\begin{array}{c}\text { Worst }(95 \% \\
\text { confidence interval }(\%))\end{array}$ & $\begin{array}{l}\text { 2nd } \\
\text { Worst }\end{array}$ & $\begin{array}{c}\text { 3rd } \\
\text { Worst }\end{array}$ & $\begin{array}{l}\text { Not } \\
\text { ranked }\end{array}$ & \\
\hline Abdominal pain & 100 & $30(30)(21$ to 40$)$ & $21(21)$ & $13(13)$ & $15(15)$ & 3.80 \\
\hline Abdominal distension & 100 & $6(6)(2$ to 13$)$ & $15(15)$ & $17(17)$ & $14(14)$ & $2 \cdot 82$ \\
\hline Abnormal bowel habit & 100 & $20(20)(13$ to 29$)$ & $19(19)$ & $18(18)$ & $16(16)$ & $3 \cdot 34$ \\
\hline Constant lethargy & 96 & $14(15)(8$ to 23$)$ & $15(16)$ & $11(11)$ & $15(16)$ & 2.99 \\
\hline Backache & 75 & $6(8)(3$ to 17$)$ & $7(9)$ & $10(13)$ & $24(32)$ & $2 \cdot 29$ \\
\hline Early satiety & 73 & 1 (1) $(0.03$ to 7$)$ & 1 (1) & $1(1)$ & $56(77)$ & 0.55 \\
\hline Excess wind & 66 & 8 (12) (5 to 22$)$ & $9(14)$ & $11(17)$ & $16(24)$ & 2.67 \\
\hline Nausea & 62 & $6(10)(4$ to 20$)$ & $4(6)$ & $10(16)$ & $23(37)$ & $2 \cdot 16$ \\
\hline Headache & 61 & $2(3)(0 \cdot 4$ to 11$)$ & $1(2)$ & 0 & $28(46)$ & $1 \cdot 39$ \\
\hline Urinary problems & 56 & 2 (4) $(0.4$ to 12$)$ & $2(4)$ & $4(7)$ & $33(59)$ & $1 \cdot 23$ \\
\hline Heartburn or dyspepsia & 51 & 1 (2) $(0.05$ to 10$)$ & $4(8)$ & $2(4)$ & $32(63)$ & $1 \cdot 18$ \\
\hline Dry skin & 28 & $0 \quad(0$ to 12$)$ & 0 & 0 & $24(86)$ & 0.25 \\
\hline Other symptoms $\dagger$ & 20 & $4(20)(6$ to 44$)$ & $2(10)$ & $2(10)$ & $10(50)$ & $2 \cdot 30$ \\
\hline
\end{tabular}

^Percentage calculated only from number of patients with that symptom

†Defined as thigh pain (five patients), bad breath (five), dizzy spells (five), generalised aches (four), and rectal dissatisfaction (one). patients with the symptom) was computed to allow a comparison of the relative severity of each symptom but was not formally analysed.

Forty four patients rated a non-colonic symptom as being the worst, constant lethargy, nausea, backache, and excess wind being particularly prominent; this was reflected by their severity score (table). Some noncolonic symptoms-for example, early satietyalthough common were not ranked as particularly severe. Fifty three patients had evidence of anxiety or depression, or both. Patients with psychological symptoms tended to report more symptoms than those without, but the ranking patterns were not significantly different in the two groups.

\section{Comment}

This study confirmed the high prevalence of noncolonic symptoms in the irritable bowel syndrome and indicated that some of these can be as intrusive as the classic symptoms of abdominal pain, distension, and abnormal bowel habit. It might be argued that these findings are due to our having studied an excess of patients with psychological problems, but the prevalence of such patients in this study $(53 \%)$ is in accord with previous reports. ${ }^{3}$ In addition, the ranking pattern was unaffected by the presence of psychological problems. Patients with the irritable bowel syndrome tend to be regarded as complainers. This view is not supported by our observation that the control symptom, dry skin, received by far the lowest ranking and was the least common complaint.

Some symptoms were equally common but differed considerably in their intrusiveness. Those perceived as severe may lead to inappropriate investigation. Common but less severe symptoms, such as early satiety, may be useful in discriminating the irritable bowel syndrome from other gastrointestinal disorders, and this is currently under investigation. Therapeutic trials in the irritable bowel syndrome often produce conflicting data, ${ }^{4}$ possibly because investigators fail to record non-colonic symptoms. This may also explain why overall improvement without a change in the recorded symptoms is sometimes observed. ${ }^{5}$ Patients will probably cope with these disruptive symptoms better if they are reassured that they are part of their syndrome and do not have a more sinister cause.

1 Whorwell PJ, McCallum M, Creed FH, Roberts CT. Non-colonic features of irritable bowel syndrome. Gut 1986;27:37-40.

2 Zigmond AS, Snaith RP. The hospital anxiety and depression scale. Acta Psych Scand 1983;67:361-70.

Creed FH, Guthrie E. Psychological factors in the irritable bowel syndrome. Gut 1987;28:1307-18.

+ Klein KB. Controlled treatment trials in the irritable bowel syndrome: a critique. Gastroenterology 1988;95:232-41

5 Prior A, Whorwell PJ. Double blind study of ispagula in irritable bowel syndrome. Gut 1987;28:1510-3.

(Accepted I August 1989) 